\title{
Expression, association with clinicopathological features and prognostic potential of CEP55, p-Akt, FoxM1 and MMP-2 in astrocytoma
}

\author{
SAISAI NIE ${ }^{1}$, LEI LOU ${ }^{1}$, JUAN WANG ${ }^{1}$, JINFENG CUI ${ }^{1}$, WENXIN WU ${ }^{1}$, QING ZHANG ${ }^{1}$, YING LIU ${ }^{1}$, \\ LINGRUI SU ${ }^{1}$, YING CHANG ${ }^{1}$, WENLI GUO ${ }^{1}$, HAITAO SHEN ${ }^{2}$, LINGXIAO XING ${ }^{2}$ and YUEHONG LI ${ }^{1}$ \\ ${ }^{1}$ Department of Pathology, The Second Hospital of Hebei Medical University, Shijiazhuang, Hebei 050000; \\ ${ }^{2}$ Laboratory of Pathology, Hebei Medical University, Shijiazhuang, Hebei 050017, P.R. China
}

Received October 12, 2019; Accepted April 27, 2020

DOI: $10.3892 / \mathrm{ol} .2020 .11742$

\begin{abstract}
Centrosomal protein 55 (CEP55) is a member of the centrosomal-associated protein family and participates in the regulation of cytokinesis during cell mitosis. However, aberrant CEP55 protein expression has been observed in human tumors. In addition, CEP55 regulates the biological functions of tumors by inducing the Akt pathway and upregulating forkhead box protein M1 (FoxM1) and matrix metalloproteinase-2 (MMP-2). In the present study, the levels, clinicopathological features and prognostic potential of CEP55, phosphorylated Akt (p-Akt), FoxM1 and MMP-2 in astrocytoma were evaluated. CEP55, p-Akt, FoxM1 and MMP-2 levels were examined in 27 normal brain tissues and 262 astrocytoma tissues by using immunohistochemistry. Furthermore, Kaplan-Meier analysis and Cox proportional hazards models were applied to predict the prognosis of patients with astrocytoma. The results indicated that expression levels of CEP55 and other proteins were elevated in human astrocytoma compared with those in normal brain tissue. The levels of the selected proteins were increased as the tumor grade increased. Furthermore, CEP55 expression was positively correlated with p-Akt, FoxM1 and MMP-2 levels in astrocytoma. Overall survival analysis revealed that patient prognosis was associated with CEP55, p-Akt, FoxM1 and MMP-2 levels, as well as with the tumor grade and patient age. Furthermore, CEP55, FoxM1, tumor grade and patient age were independent prognostic factors in astrocytoma according to multivariate analysis. Taken together, the present results suggested that CEP55, p-Akt, FoxM1 and MMP-2 have crucial roles in the progression and prognosis of human astrocytoma and that CEP55 and FoxM1 may be potential therapeutic targets.
\end{abstract}

Correspondence to: Dr Yuehong Li, Department of Pathology, The Second Hospital of Hebei Medical University, 215 Heping Western Road, Shijiazhuang, Hebei 050000, P.R. China

E-mail: liyuehong1993@126.com

Key words: centrosomal protein 55, forkhead box protein M1, astrocytoma, immunohistochemistry, prognosis

\section{Introduction}

Astrocytoma is a common type of human glioma and a primary lethal central nervous system (CNS) tumor. High invasion and poor prognosis are typical features of this tumor type. In particular, patients with glioblastoma, the most aggressive form of malignant astrocytoma, only have a median survival time of 9-12 months $(1,2)$. Despite multimodal treatment, including surgical resection followed by chemotherapy and radiotherapy, no significant improvements in clinical outcomes have been observed in patients with astrocytoma. Therefore, novel molecular markers or targets may contribute to the diagnosis and treatment of malignant brain tumors.

Isocitrate dehydrogenase (IDH) mutations are commonly detected in low-grade diffuse gliomas and evidence supports that this mutation is a driver of gliomagenesis. IDH1 mutations represent a distinguishing feature of low-grade glioma and secondary glioblastoma (GBM) (3). Of note, patients with IDH1 mutations have a significantly better prognosis than patients with wild-type IDH1 (4). Based on the updated 2016 edition of the World Health Organization (WHO) classification of CNS tumors, IDH1 has become a necessary marker for analysis of tumor classification (5). Therefore, IDH1 mutations are important reference indices for the pathological diagnosis and prognostic evaluation of patients with glioma.

Centrosomal protein 55 (CEP55) is a member of the CEP protein family and was initially identified as a centrosomeand midbody-associated protein that regulates cytokinesis (6). Overexpression of CEP55 leads to cytokinesis defects and increased multinucleated cells, which may cause tumorigenesis. In recent years, high CEP55 expression has been indicated in certain types of human tumors and to be correlated with poor prognosis in patients with malignancies (7-9). A study also indicated that overexpression of CEP55 enhances the cell proliferation and aggressiveness in gastric carcinoma, whereas CEP55 knockdown inhibits these processes (10). Furthermore, numerous studies have indicated that CEP55 regulates the biological behaviors of tumors through the phosphatidylinositol 3-kinase (PI3K)/Akt signaling pathway $(11,12)$. For instance, in osteosarcoma and lung cancer, CEP55 promoted the proliferation, migration and invasion of tumor cells via the 
PI3K/Akt signaling pathway $(13,14)$. In addition, CEP55 has been indicated to combine with the catalytic subunit $\alpha$ of PI3K, also known as p110. This interaction enhances the stability of the subunit, resulting in increased Akt activation, as demonstrated by an increase in S473 phosphorylation $(11,13)$.

Forkhead box protein M1 (FoxM1) is a member of the Fox family and is expressed mainly as a transcription factor in normal proliferating cells (15). Furthermore, FoxM1 is upregulated in most human solid malignant tumor types, including cervical carcinoma, lung cancer and glioma (16-18). FoxM1 is localized in the nucleus of tumor cells and is regulated by multiple cytokines and signaling pathways, including the PI3K/Akt pathway. Cross-talk between the Akt and FoxM1 pathways has been demonstrated (19-21). Various studies suggested that Akt upregulates FoxM1 expression in osteosarcoma and that downregulation of Akt by small interfering RNA inhibits FoxM1 expression in prostate cancer and melanoma (20-22). In addition, FoxM1 is able to increase the expression of matrix metalloproteinase-2 (MMP-2) in various human tumor types, thereby promoting the invasion and metastasis of tumors. For instance, downregulation of FoxM1 expression in esophageal squamous cell carcinoma cells may cause a significant decrease in MMP-2 expression (23). Ahmad et al (24) reported that upregulation of FoxM1 expression in breast cancer cells markedly increased MMP-2 expression and promoted tumor invasion and metastasis. Furthermore, FoxM1/MMP-2 and CEP55 are correlated in certain tumors. Indeed, in oral squamous cell carcinoma, CEP55 increases the expression of FoxM1 and MMP-2 proteins, thereby promoting tumor cell migration and invasion (25). However, the possible roles and putative associations among CEP55, phosphorylated (p-)Akt, FoxM1 and MMP-2 in astrocytoma remain to be fully elucidated.

Accordingly, in the present study, the levels of CEP55, p-Akt, FoxM1 and MMP-2 in astrocytoma were determined and the associations of these proteins with the clinicopathological features of astrocytoma were investigated. In addition, survival analysis was performed to identify factors that affect the prognosis of patients with astrocytoma.

\section{Materials and methods}

Tissue specimens and clinical data. The present study was a retrospective study. A total of 262 cases were included and their archival paraffin-embedded astrocytoma tissue specimens collected between May 2011 and February 2016 at the Department of Pathology of the Second Hospital of Hebei Medical University (Shijiazhuang, China) were obtained. The present study was approved by the Ethics Committees of the Second Hospital of Hebei Medical University (Shijiazhuang, China) and informed consent was obtained from each participant. The patients included 155 males and 107 females (mean age, 53.0 years; range, 17-84 years) who had a confirmed histological diagnosis of astrocytoma according to the WHO histological classification of CNS tumors. Among the 262 astrocytoma cases, 81 were diagnosed with diffuse astrocytoma (DA; WHO grade II), 101 were diagnosed with anaplastic astrocytoma (AA; WHO grade III) and 80 were diagnosed with GBM (WHO grade IV). The Second Hospital of Hebei Medical University (Shijiazhuang, China) is an authoritative base for glioma diagnosis and treatment in the North China Plain. More than 100 cases of glioma are diagnosed annually here, of which the number of patients with glioblastoma is the largest. However, this area is close to Beijing, the capital of China, and Tianjin, a municipality directly under the central government. Patients with high suspicion of GBM based on clinical symptoms and imaging findings were more likely to go to hospital in Beijing and Tianjin for surgical treatment. Therefore, the number of GBM specimens in the present study is relatively low and insufficient. However, this situation was also encountered in another study performed in Zhengzhou (Henan, China) (26). The 262 astrocytoma tissues included 98 IDH1-mutant and 164 wild-type IDH1 astrocytoma cases (Fig. 1). In addition, 27 normal brain tissue specimens were acquired from individuals who died in motor vehicle collisions between January 2008 and April 2016. These samples included 16 males and 11 females (mean age, 47 years; range, 23-78 years), which were age- and sex-matched with the astrocytoma case group. Their families provided informed consent for the use of these tissues and the use of the 27 normal brain tissue specimens was also approved by the Ethics Committee of the Second Hospital of Hebei Medical University (Shijiazhuang, China). The overall survival time was calculated from the date of diagnosis to the date of death or the date of the last follow-up or last time-point the patient was known to be alive, defined as censored (last evaluated November 30, 2017).

Immunohistochemical staining. Immunohistochemical staining for CEP55, p-Akt, FoxM1, MMP-2 and IDH1 proteins in astrocytoma sections was performed using a ready-to-use Biotin-Streptavidin/Horseradish peroxidase (HRP) Detection system (OriGene Technologies, Inc.). Paraffin sections ( $4 \mu \mathrm{m})$ were deparaffinized in xylene and then rehydrated with alcohol; heat-induced antigen recovery was performed in citrate buffer ( $\mathrm{pH} 6.0$ ) for $5 \mathrm{~min}$ at $120^{\circ} \mathrm{C}$ or EDTA antigen retrieval solution ( $\mathrm{pH} \mathrm{8.0)}$ ) for $5 \mathrm{~min}$ at $120^{\circ} \mathrm{C}$, followed by quenching of the endogenous peroxidase using $3 \% \mathrm{H}_{2} \mathrm{O}_{2}$ for $20 \mathrm{~min}$ at room temperature. Goat serum (OriGene Technologies, Inc.) was used for blocking nonspecific binding sites for 3-4 h at room temperature. Slides were then incubated with primary antibodies [anti-CEP55 (1:400 dilution; Abcam; ab214302); anti-p-Akt (1:150 dilution; Gene Tex; GTX28932); anti-FoxM1 (1:600 dilution; Abcam; ab207298); anti-MMP-2 (1:200 dilution; Gene Tex; GTX104577); mouse anti-IDH1R132H (working solution; OriGene Technologies, Inc.; ZM-0447)] at $4^{\circ} \mathrm{C}$ overnight. After washing with PBS, a Biotin-Streptavidin HRP Detection system (working solution; OriGene Technologies, Inc.; SP-9000/9001/9002) was used for detection of the antigen-antibody complex, which was visualized with diaminobenzidine as the chromogen. Finally, counterstaining was performed using Mayer's hematoxylin and the sections were dehydrated in alcohol prior to mounting. As a negative control, the primary antibody was omitted; no staining was observed.

Scoring of staining. Immunohistochemical staining was assessed using semi-quantitative scoring by two independent investigators (YL and JC) who were blinded to the histopathological features and clinicopathological data of the samples. Before the scoring was performed, a set of criteria were 


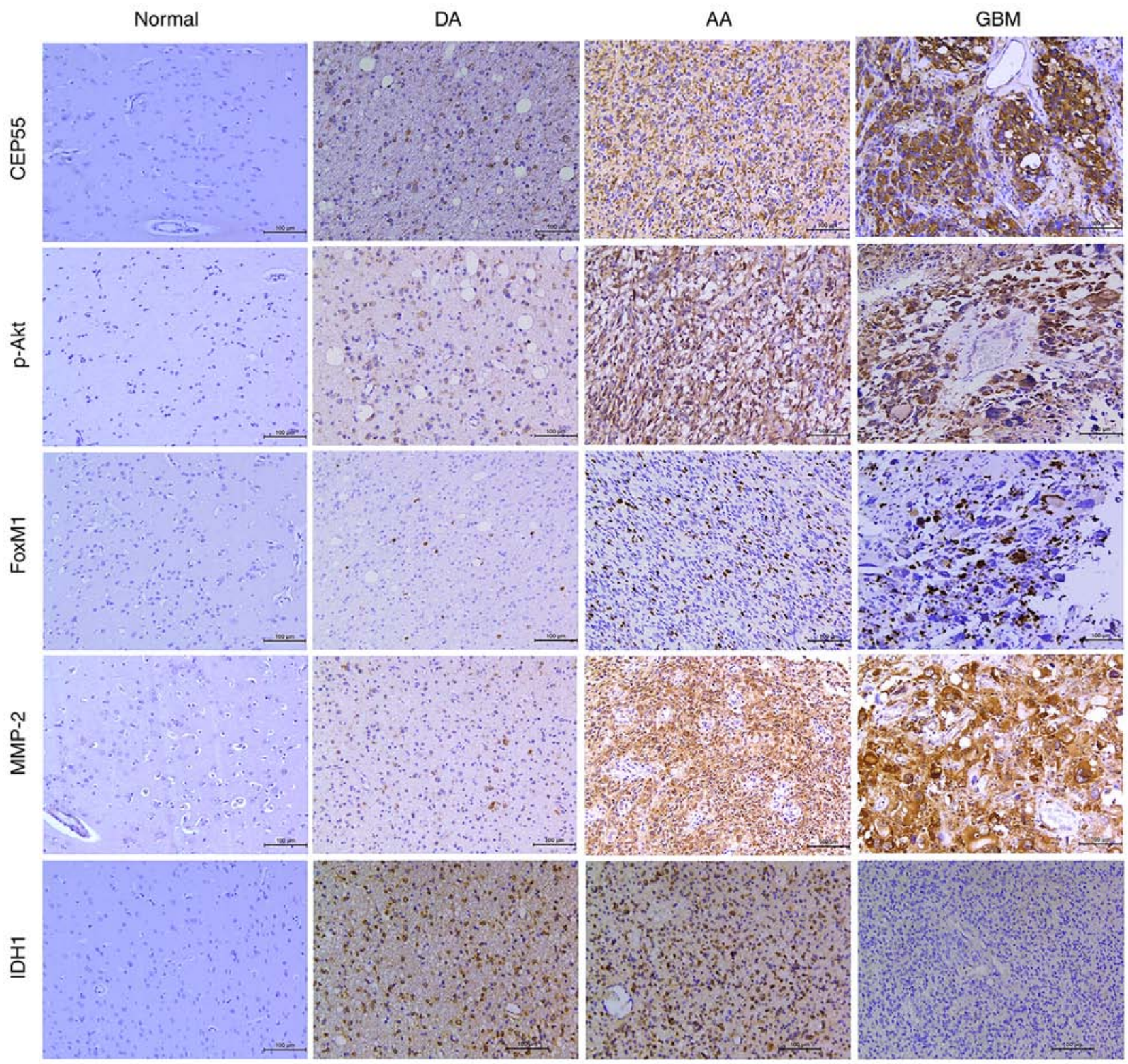

Figure 1. CEP55, p-Akt, FoxM1, MMP-2 and IDH1 proteins in astrocytoma were detected by immunohistochemistry. CEP55 and IDH1 were localized in the cytoplasm of tumor cells. p-Akt and MMP-2 protein were mainly expressed in the cytoplasm, with a small amount in the cell nuclei. FoxM1 protein was observed only in the cell nuclei. Low expression of CEP55, p-Akt, FoxM1 and MMP-2 was present in normal brain tissue and DA, while high expression was observed in AA and GBM. Staining for IDH1 was negative in normal brain tissue and GBM and strongly positive in DA and AA (magnification, x200; scale bar, $100 \mu \mathrm{m}$ ). DA, diffuse astrocytoma; AA, anaplastic astrocytoma; GBM, glioblastoma; FoxM1, forkhead box protein M1; MMP-2, matrix metalloproteinase-2; p-Akt, phosphorylated Akt; CEP55, centrosomal protein 55; IDH, isocitrate dehydrogenase.

established based on the literature with minor modifications in terms of the percentage scores of positive cells and the final score (27-30). The degree of staining was determined by the percentage of positive cells and the staining intensity. Cells that were stained with yellow or brown color were considered as positively-stained cells. Necrotic areas and areas with extensive bleeding were not included. Positive expression of CEP55, p-Akt and MMP-2 proteins was identified in the cytoplasm and/or nucleus. Sections were observed and five high-power fields (magnification, $\mathrm{x}$ 40) were randomly selected under a light microscope. The percentage of positive cells was divided into four grades (percentage scores), as follows: $1, \leq 10 \% ; 2,11-50 \%$; $3,51-80 \%$; and $4,>80 \%$. The staining intensity was divided into four grades (intensity scores), as follows: 0 , no staining; 1 , light yellow; 2, brown; and 3, dark brown. The staining degree was calculated as follows: Overall score=percentage score $\mathrm{x}$ intensity score. If the overall score was $0-4$, the sample was classified as having low expression; if the overall score was 5 or more, the sample was classified as having high expression. FoxM1 protein was localized in the nucleus. Percentage scoring for FoxM1 protein was as follows: $0, \leq 5 \%$; 1, 6-25\%; 2 , $26-50 \% ; 3,51-75 \%$; and 4, $>75 \%$; while the intensity scoring was as follows: 0, no staining; 1, light yellow; 2, brown; and 3, dark brown. The staining degree was calculated as follows: Overall score $=$ percentage score $\mathrm{x}$ intensity score. Overall scores of 0-4 indicated low expression, whereas overall scores of 5 or more indicated high expression. Based on this, the patients we divided into low and high expression groups. 
Table I. CEP55, p-Akt, FoxM1 and MMP-2 levels in normal brain tissues and astrocytoma tissues.

\begin{tabular}{lccccccccr}
\hline Tissue type & $\mathrm{n}$ & CEP55 & P-value & $\mathrm{p}$-Akt & P-value & FoxM1 & P-value & MMP-2 & P-value \\
\hline Normal & 27 & $2(7.4)$ & $<0.001$ & $2(7.4)$ & $<0.001$ & $0(0)$ & $<0.001$ & $1(3.7)$ & $<0.001$ \\
Astrocytoma & 262 & $170(64.9)$ & & $145(55.3)$ & & $136(51.9)$ & & $156(59.5)$ & \\
\hline
\end{tabular}

Values are expressed as n (\%). CEP55, centrosomal protein 55; p-Akt, phosphorylated Akt; FoxM1, forkhead box protein M1; MMP-2, matrix metalloproteinase-2.

Table II. Clinicopathological characteristics of CEP55, p-Akt, FoxM1 and MMP-2 in astrocytoma.

\begin{tabular}{|c|c|c|c|c|c|c|c|c|c|c|c|c|c|}
\hline \multirow{2}{*}{$\begin{array}{l}\text { Pathological } \\
\text { characteristic }\end{array}$} & \multirow[b]{2}{*}{$\mathrm{n}$} & \multicolumn{2}{|c|}{ CEP55 } & \multirow[b]{2}{*}{ P-value } & \multicolumn{2}{|c|}{ p-Akt } & \multirow[b]{2}{*}{ P-value } & \multicolumn{2}{|c|}{ FoxM1 } & \multirow[b]{2}{*}{ P-value } & \multicolumn{2}{|c|}{ MMP-2 } & \multirow[b]{2}{*}{ P-value } \\
\hline & & High & Low & & High & Low & & High & Low & & High & Low & \\
\hline Age (years) & & & & 0.046 & & & 0.066 & & & 0.014 & & & $<0.001$ \\
\hline$<50$ & 129 & 76 & 53 & & 64 & 65 & & 57 & 72 & & 60 & 69 & \\
\hline$\geq 50$ & 133 & 94 & 39 & & 81 & 52 & & 79 & 54 & & 96 & 37 & \\
\hline Sex & & & & 0.056 & & & 0.416 & & & 0.523 & & & 0.144 \\
\hline Male & 155 & 104 & 51 & & 89 & 66 & & 83 & 72 & & 98 & 57 & \\
\hline Female & 107 & 66 & 41 & & 56 & 51 & & 53 & 54 & & 58 & 49 & \\
\hline Tumor size $(\mathrm{cm})$ & & & & 0.484 & & & 0.163 & & & 0.614 & & & 0.070 \\
\hline$<5.0$ & 129 & 81 & 48 & & 77 & 52 & & 69 & 60 & & 45 & 84 & \\
\hline$\geq 5.0$ & 133 & 89 & 44 & & 65 & 68 & & 67 & 66 & & 61 & 72 & \\
\hline Tumor grade & & & & $<0.001$ & & & $<0.001$ & & & $<0.001$ & & & $<0.001$ \\
\hline DA (WHOII) & 81 & 26 & 55 & & 22 & 59 & & 13 & 68 & & 19 & 62 & \\
\hline AA (WHOIII) & 101 & 76 & 25 & & 59 & 42 & & 63 & 38 & & 75 & 26 & \\
\hline GBM (WHOIV) & 80 & 68 & 12 & & 64 & 16 & & 60 & 20 & & 62 & 18 & \\
\hline IDH1 status & & & & 0.491 & & & 0.278 & & & 0.080 & & & 0.099 \\
\hline Mutant & 98 & 61 & 37 & & 50 & 48 & & 44 & 54 & & 52 & 46 & \\
\hline Wild-type & 164 & 109 & 55 & & 95 & 69 & & 92 & 72 & & 104 & 60 & \\
\hline
\end{tabular}

CEP55, centrosomal protein 55; p-Akt, phosphorylated Akt B; FoxM1, Forkhead box protein M1; MMP-2, matrix metalloproteinase-2; IDH1, isocitrate dehydrogenase 1; DA, diffuse astrocytoma; AA, anaplastic astrocytoma; GBM, glioblastoma; WHO, World Health Organization.

Statistical analysis. All statistical analyses were performed using SPSS 21.0 software (IBM Corp.). $\chi^{2}$ tests were used to compare the staining results for target proteins in different groups and for comparisons with clinicopathological characteristics. The correlations between CEP55 and other proteins were determined using nonparametric Spearman's correlation tests. Kaplan-Meier analysis was performed to draw overall survival curves and statistical significance was assessed using log-rank tests. Univariate and multivariate analysis were performed using the Cox proportional hazard regression model. $\mathrm{P}<0.05$ was considered to indicate statistical significance.

\section{Results}

CEP55, $p$-Akt, FoxM1 and MMP-2 levels in normal brain tissues and astrocytoma tissues. Immunohistochemical analyses were performed to determine the expression levels and distributions of target proteins. Representative images and the results are provided in Fig. 1 and Table I, respectively. For the 27 normal brain tissues, high expression of CEP55, p-Akt, FoxM1 and MMP-2 was observed in 2 (7.4\%), 2 (7.4\%), $0(0.0 \%)$ and $1(3.7 \%)$ cases, respectively. For the 262 astrocytoma tissues, high expression of these proteins was observed in 170 (64.9\%), 145 (55.3\%), $136(51.9 \%)$ and $156(59.5 \%)$ of cases, respectively. Thus, high expression of these markers was significantly more frequent in astrocytoma than in normal brain tissue $(\mathrm{P}<0.05)$.

Clinicopathological characteristics of CEP55, p-Akt, FoxM1 and MMP-2 in astrocytoma. Next, the associations of protein levels and clinicopathological features in patients with astrocytoma were assessed by $\chi^{2}$ tests and Spearman correlation analysis. As presented in Table II, the expression levels of CEP55, FoxM1 and MMP-2 in astrocytoma were positively associated with patient age $(\mathrm{P}<0.05)$; however, sex and tumor size were not significantly associated with the expression levels of the three proteins (CEP55, FoxM1 and 

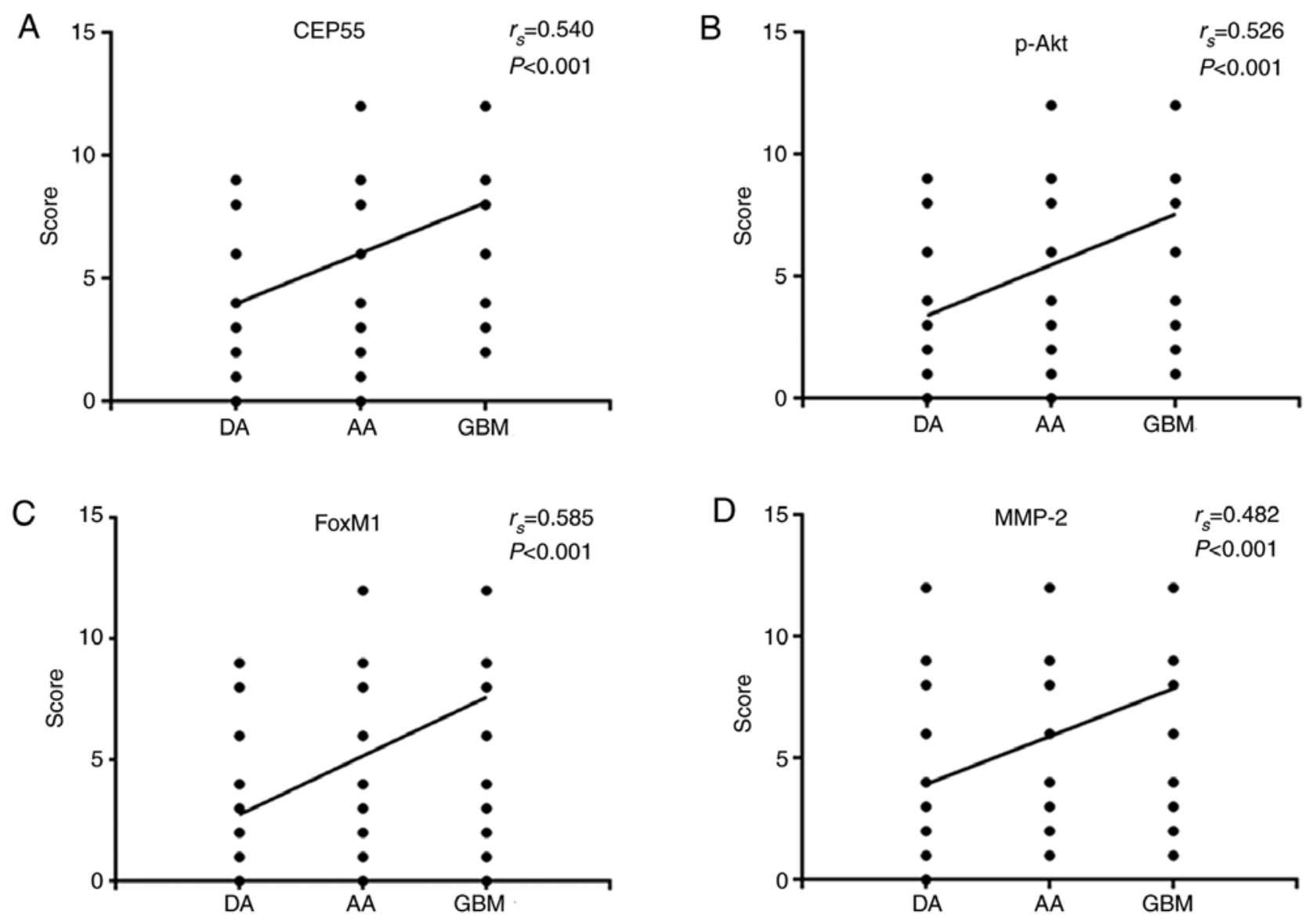

Figure 2. Scatter plot of the Spearman correlation analysis. The levels of (A) CEP55, (B) p-Akt, (C) FoxM1 and (D) MMP-2 were correlated with the tumor grade $(\mathrm{P}<0.01)$. FoxM1, forkhead box protein M1; MMP-2, matrix metalloproteinase-2; p-Akt, phosphorylated Akt; CEP55, centrosomal protein 55; DA, diffuse astrocytoma; AA, anaplastic astrocytoma; GBM, glioblastoma.

MMP-2; P>0.05; Table II). High levels of p-Akt were not associated with age, sex or tumor size in patients $(\mathrm{P}>0.05$; Table II). Furthermore, Spearman correlation analysis indicated that the levels of CEP55, p-Akt, FoxM1 and MMP-2 were correlated with the tumor grade $\left(\mathrm{r}_{\mathrm{CEP} 55}=0.540, \mathrm{P}<0.05\right.$; $\mathrm{r}_{\mathrm{p}-\mathrm{Akt}}=0.526, \mathrm{P}<0.05 ; \mathrm{r}_{\mathrm{FoxM} 1}=0.585, \mathrm{P}<0.05 ; \mathrm{r}_{\mathrm{MMP}-2}=0.482$, $\mathrm{P}<0.05$; Fig. 2). As the tumor grade increased, the levels of all of the four proteins also increased $(\mathrm{P}<0.05$; Table II). However, IDH1 mutations were not associated with the expression of CEP55, p-Akt, FoxM1 and MMP-2 in astrocytoma $(\mathrm{P}>0.05$; Table II). Taken together, these results indicated that CEP55, p-Akt, FoxM1 and MMP-2 may have roles in astrocytoma progression.

Correlations among CEP55, p-Akt, FoxM1 and MMP-2 levels in astrocytoma. As presented in Table III, Spearman's rank correlation analyses revealed that CEP55, p-Akt, FoxM1 and MMP-2 levels were positively correlated in astrocytoma and DA $(\mathrm{P}<0.05)$. In AA, correlations were observed between all proteins $(\mathrm{P}<0.05)$, except for the correlation between FoxM1 and MMP-2, which was not significant. In GBM, a positive correlation was observed for all comparisons $(\mathrm{P}<0.05)$, while there was no significant correlation between p-Akt and FoxM1 and between FoxM1 and MMP-2. These results suggested that CEP55 may interact with the other proteins to mediate invasive growth of astrocytoma.
Prognostic value of CEP55, $p$-Akt, FoxM1 and MMP-2 in patients with astrocytoma. As presented in Fig. 3, overall survival analysis indicated that higher expression levels of CEP55, p-Akt, FoxM1 and MMP-2 were associated with significantly poorer overall survival than that for patients with lower levels of these proteins. Indeed, CEP55, p-Akt, FoxM1 and MMP-2 levels were correlated with patient prognosis $(\mathrm{P}<0.05$; Fig. 3A-D). Other conventional prognostic factors, including tumor grade and patient age, were correlated with patient prognosis $(\mathrm{P}<0.05$; Fig. $3 \mathrm{E}$ and $\mathrm{F})$. The median survival time in patients with GBM was only 13 months. Furthermore, the prognosis worsened as the patient age increased. However, sex and tumor size did not influence the clinical prognosis $(\mathrm{P}>0.05$; Fig. $3 \mathrm{G}$ and $\mathrm{H}$, respectively). Further analysis using univariate and multivariate Cox proportional hazards models revealed that CEP55 and FoxM1 levels, tumor grade and patient age were independent prognostic factors $(\mathrm{P}<0.05$; Table IV).

\section{Discussion}

Astrocytoma is a common type of brain tumor in humans. Diffuse astrocytoma (also known as low-grade astrocytoma) and anaplastic astrocytoma frequently progress to glioblastoma with highly proliferative and invasive phenotypes. Despite advanced therapeutic strategies, the prognosis of malignant 
Table III. Correlations among CEP55, p-Akt, FoxM1 and MMP-2 levels in astrocytoma.

A, Astrocytoma

\begin{tabular}{|c|c|c|c|c|c|c|c|c|c|c|c|c|}
\hline \multirow[b]{2}{*}{ Protein } & \multicolumn{2}{|c|}{$\mathrm{p}$-Akt } & \multirow[b]{2}{*}{$\mathrm{r}$} & \multirow[b]{2}{*}{ P-value } & \multicolumn{2}{|c|}{ FoxM1 } & \multirow[b]{2}{*}{$\mathrm{r}$} & \multirow[b]{2}{*}{ P-value } & \multicolumn{2}{|c|}{ MMP-2 } & \multirow[b]{2}{*}{$\mathrm{r}$} & \multirow[b]{2}{*}{ P-value } \\
\hline & High & Low & & & High & Low & & & High & Low & & \\
\hline CEP55 & & & 0.594 & $<0.001$ & & & 0.508 & $<0.001$ & & & 0.501 & $<0.001$ \\
\hline High & 131 & 39 & & & 120 & 50 & & & 132 & 38 & & \\
\hline Low & 14 & 78 & & & 16 & 76 & & & 24 & 68 & & \\
\hline p-Akt & & & & & & & 0.365 & $<0.001$ & & & 0.464 & $<0.001$ \\
\hline High & & & & & 99 & 46 & & & 116 & 29 & & \\
\hline Low & & & & & 37 & 80 & & & 40 & 77 & & \\
\hline FoxM1 & & & & & & & & & & & 0.405 & $<0.001$ \\
\hline High & & & & & & & & & 107 & 29 & & \\
\hline Low & & & & & & & & & 49 & 77 & & \\
\hline
\end{tabular}

$\mathrm{B}, \mathrm{DA}(\mathrm{WHOII})$

\begin{tabular}{|c|c|c|c|c|c|c|c|c|c|c|c|c|}
\hline \multirow[b]{2}{*}{ Protein } & \multicolumn{2}{|c|}{ p-Akt } & \multirow[b]{2}{*}{$\mathrm{r}$} & \multirow[b]{2}{*}{ P-value } & \multicolumn{2}{|c|}{ FoxM1 } & \multirow[b]{2}{*}{$\mathrm{r}$} & \multirow[b]{2}{*}{ P-value } & \multicolumn{2}{|c|}{ MMP-2 } & \multirow[b]{2}{*}{$\mathrm{r}$} & \multirow[b]{2}{*}{ P-value } \\
\hline & High & Low & & & High & Low & & & High & Low & & \\
\hline CEP55 & & & 0.531 & $<0.001$ & & & 0.492 & $<0.001$ & & & 0.556 & $<0.001$ \\
\hline High & 16 & 10 & & & 11 & 15 & & & 15 & 11 & & \\
\hline Low & 6 & 49 & & & 2 & 53 & & & 4 & 51 & & \\
\hline p-Akt & & & & & & & 0.338 & 0.002 & & & 0.448 & $<0.001$ \\
\hline High & & & & & 8 & 14 & & & 12 & 10 & & \\
\hline Low & & & & & 5 & 54 & & & 7 & 52 & & \\
\hline FoxM1 & & & & & & & & & & & 0.393 & $<0.001$ \\
\hline High & & & & & & & & & 8 & 5 & & \\
\hline Low & & & & & & & & & 11 & 57 & & \\
\hline
\end{tabular}

C, AA (WHOIII)

\begin{tabular}{|c|c|c|c|c|c|c|c|c|c|c|c|c|}
\hline \multirow[b]{2}{*}{ Protein } & \multicolumn{2}{|c|}{ p-Akt } & \multirow[b]{2}{*}{$\mathrm{r}$} & \multirow[b]{2}{*}{ P-value } & \multicolumn{2}{|c|}{ FoxM1 } & \multirow[b]{2}{*}{$\mathrm{r}$} & \multirow[b]{2}{*}{ P-value } & \multicolumn{2}{|c|}{ MMP-2 } & \multirow[b]{2}{*}{$\mathrm{r}$} & \multirow[b]{2}{*}{ P-value } \\
\hline & High & Low & & & High & Low & & & High & Low & & \\
\hline CEP55 & & & 0.494 & $<0.001$ & & & 0.312 & 0.001 & & & 0.240 & 0.016 \\
\hline High & 55 & 21 & & & 54 & 22 & & & 61 & 15 & & \\
\hline Low & 4 & 21 & & & 9 & 16 & & & 14 & 11 & & \\
\hline p-Akt & & & & & & & 0.216 & 0.030 & & & 0.284 & 0.004 \\
\hline High & & & & & 42 & 17 & & & 50 & 9 & & \\
\hline Low & & & & & 21 & 21 & & & 25 & 17 & & \\
\hline FoxM1 & & & & & & & & & & & 0.150 & 0.133 \\
\hline High & & & & & & & & & 50 & 13 & & \\
\hline Low & & & & & & & & & 25 & 13 & & \\
\hline
\end{tabular}

D, GBM (WHOIV)

\begin{tabular}{|c|c|c|c|c|c|c|c|c|c|c|c|c|}
\hline \multirow[b]{2}{*}{ Protein } & \multicolumn{2}{|c|}{ p-Akt } & \multirow[b]{2}{*}{$\mathrm{r}$} & \multirow[b]{2}{*}{ P-value } & \multicolumn{2}{|c|}{ FoxM1 } & \multirow[b]{2}{*}{$\mathrm{r}$} & \multirow[b]{2}{*}{ P-value } & \multicolumn{2}{|c|}{ MMP-2 } & \multirow[b]{2}{*}{$\mathrm{r}$} & \multirow[b]{2}{*}{ P-value } \\
\hline & High & Low & & & High & Low & & & High & Low & & \\
\hline CEP55 & & & 0.490 & $<0.001$ & & & 0.323 & 0.003 & & & 0.277 & 0.013 \\
\hline High & 60 & 8 & & & 55 & 13 & & & 56 & 12 & & \\
\hline Low & 4 & 8 & & & 5 & 7 & & & 6 & 6 & & \\
\hline
\end{tabular}


Table III. Continued.

D, GBM (WHOIV)

\begin{tabular}{|c|c|c|c|c|c|c|c|c|c|c|c|c|}
\hline \multirow[b]{2}{*}{ Protein } & \multicolumn{2}{|c|}{$\mathrm{p}$-Akt } & \multirow[b]{2}{*}{$\mathrm{r}$} & \multirow[b]{2}{*}{ P-value } & \multicolumn{2}{|c|}{ FoxM1 } & \multirow[b]{2}{*}{$\mathrm{r}$} & \multirow[b]{2}{*}{ P-value } & \multicolumn{2}{|c|}{ MMP-2 } & \multirow[b]{2}{*}{$\mathrm{r}$} & \multirow[b]{2}{*}{ P-value } \\
\hline & High & Low & & & High & Low & & & High & Low & & \\
\hline $\mathrm{p}-\mathrm{Akt}$ & & & & & & & 0.072 & 0.525 & & & 0.329 & 0.003 \\
\hline High & & & & & 49 & 15 & & & 54 & 10 & & \\
\hline Low & & & & & 11 & 5 & & & 8 & 8 & & \\
\hline FoxM1 & & & & & & & & & & & 0.173 & 0.125 \\
\hline High & & & & & & & & & 49 & 11 & & \\
\hline Low & & & & & & & & & 13 & 7 & & \\
\hline
\end{tabular}

CEP55, centrosomal protein 55; p-Akt, phosphorylated Akt; FoxM1, forkhead box protein M1; MMP-2, matrix metalloproteinase-2; DA, diffuse astrocytoma; AA, anaplastic astrocytoma; GBM, glioblastoma.

Table IV. Univariate and multivariate analysis of the prognostic factors of patients with astrocytoma.

\begin{tabular}{|c|c|c|c|c|}
\hline \multirow[b]{2}{*}{ Variable } & \multicolumn{2}{|c|}{ Univariate analysis } & \multicolumn{2}{|c|}{ Multivariate analysis } \\
\hline & HR $(95 \% \mathrm{CI})$ & P-value & HR $(95 \% \mathrm{CI})$ & P-value \\
\hline CEP55 (Low vs. high expression) & $3.958(2.724-5.751)$ & $<0.001$ & $2.406(1.496-3.869)$ & $<0.001$ \\
\hline p-Akt (Low vs. high expression) & $2.543(1.855-3.485)$ & $<0.001$ & $1.174(0.801-1.722)$ & 0.410 \\
\hline FoxM1 (Low vs. high expression) & $3.423(2.482-4.721)$ & $<0.001$ & $1.871(1.298-2.696)$ & 0.001 \\
\hline MMP-2 (Low vs. high expression) & $2.492(1.798-3.454)$ & $<0.001$ & $0.827(0.560-1.221)$ & 0.339 \\
\hline Tumor grade (DA/AA vs. GBM) & $2.097(1.728-2.545)$ & $<0.001$ & $1.477(1.161-1.879)$ & 0.002 \\
\hline Age ( $<50$ years vs. $\geq 50$ years $)$ & $2.230(1.647-3.020)$ & $<0.001$ & $1.860(1.348-2.567)$ & $<0.001$ \\
\hline Sex (Female vs. male) & $1.224(0.908-1.649)$ & 0.184 & & \\
\hline Tumor size $(<5.0 \mathrm{~cm}$ vs. $\geq 5.0 \mathrm{~cm})$ & $1.020(0.763-1.365)$ & 0.893 & & \\
\hline
\end{tabular}

HR, hazard ratio; CEP55, centrosomal protein 55; p-Akt, phosphorylated Akt; FoxM1, forkhead box protein M1; MMP-2, matrix metalloproteinase-2; DA, diffuse astrocytoma; AA, anaplastic astrocytoma; GBM, glioblastoma.

astrocytoma remains poor $(1,2)$. Therefore, early diagnosis and prognostic evaluation of astrocytoma are critical for early treatment and improved survival.

CEP55 is a member of the CEP family and has important roles in mediator-dependent cellular functions, including centrosome replication, cell cycle progression and cytokinesis (6). CEP55 exhibits high expression in numerous human tumor types and high expression of CEP55 is associated with the degree of malignancy (12). Similarly, in the present study, it was demonstrated that CEP55 was upregulated in patients with astrocytoma, suggesting important roles of CEP55 in the progression of this tumor type.

After stimulation by growth factors, hormones and cytokines, Akt is phosphorylated, resulting in activation of the protein. p-Akt promotes the growth, proliferation, invasion and metastasis of cancer cells. p-Akt has been detected in various tumor types, including prostate cancer (31) and colorectal cancer (32). The levels of p-Akt were also increased in the study, indicating that Akt activation may be involved in the development or progression of astrocytoma.
FoxM1 is a key transcription factor that has important roles in embryo development, mature tissue homeostasis and carcinogenesis. Upregulation of FoxM1 has been observed in numerous malignant tumor types, including lung cancer, oropharyngeal squamous cell carcinoma and ovarian cancer (33-35). It was also revealed that FoxM1 was upregulated in astrocytoma, similar to CEP55 and p-Akt.

MMP-2 is a gelatinase that degrades the extracellular matrix and has important roles in tumor cell growth and differentiation, invasion, metastasis and tumor angiogenesis. MMP-2 is closely linked to the occurrence and development of various types of tumor, including breast cancer, ovarian cancer and lung cancer (36-38). In the present study, overexpression of MMP-2 was also observed in astrocytoma, further highlighting the importance of this proteinase in cancer.

Overall, the present results suggested that CEP55, p-Akt, FoxM1 and MMP-2 were involved in the development of astrocytoma. CEP55, FoxM1 and MMP-2 were positively associated with the age of patients in astrocytoma, but sex and tumor size were not associated with the three proteins. In 

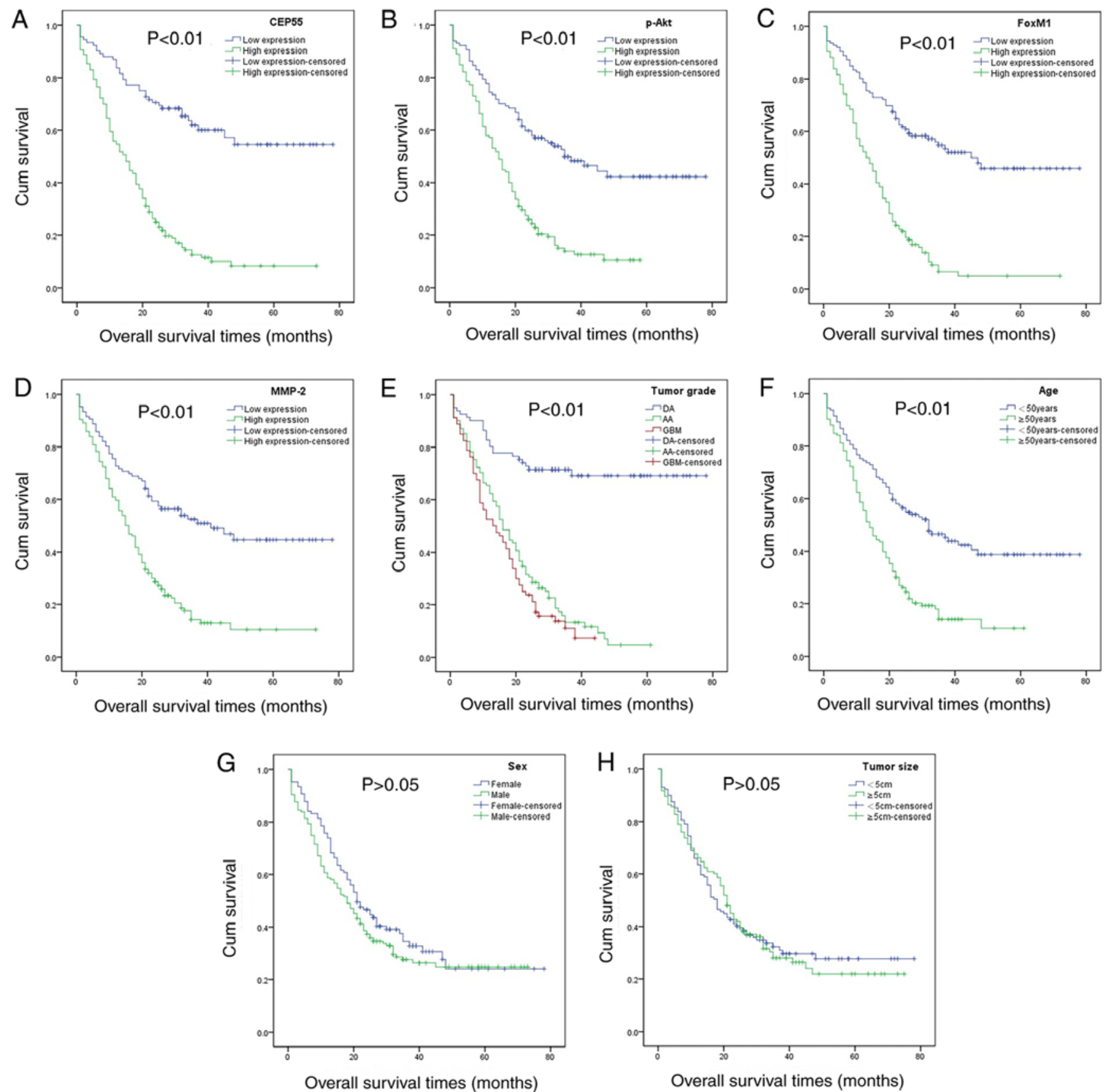

Figure 3. Kaplan-Meier analysis of overall survival in 262 cases of astrocytoma. (A-D) The survival of those patients with high levels of (A) CEP55, (B) p-Akt, (C) FoxM1 and (D) MMP-2 was significantly worse than that of patients with low levels $(\mathrm{P}<0.01)$. (E) With the increase of the tumor grade of astrocytoma, the survival time of patients was shorter $(\mathrm{P}<0.01)$. (F) Age also affected patient prognosis. The difference in survival was statistically significant with a cutoff at 50 years $(\mathrm{P}<0.01)$. $(\mathrm{G})$ The sex of patients and $(\mathrm{H})$ the tumor size were not associated with overall survival $(\mathrm{P}>0.05)$. FoxM1, forkhead box protein $\mathrm{M} 1$; MMP-2, matrix metalloproteinase-2; p-Akt, phosphorylated Akt; CEP55, centrosomal protein 55; DA, diffuse astrocytoma; AA, anaplastic astrocytoma; GBM, glioblastoma; Cum, cumulative.

addition, the levels of all four proteins increased as the tumor grade increased, further supporting the conclusions regarding the roles of these targets in astrocytoma progression.

CEP55 promotes the growth and invasion of gastric carcinoma, oral cancer, osteosarcoma and lung cancer by inducing the PI3K/Akt pathway and upregulating FoxM1 $(10-14,25)$. Chen et al (25), indicated that oral cancer cell motility is promoted by CEP55/FoxM1-induced MMP-2 overexpression and activation. In addition, FoxM1 is regulated by numerous signaling pathways, including the Akt signaling pathway. For instance, in melanoma and osteosarcoma, Akt modulates
FoxM1 protein expression $(19,20,22)$. Inhibition of Akt activity or expression results in decreased FoxM1 expression. In prostate cancer, the expression levels of Akt and FoxM1 are also positively correlated (21). In addition, FoxM1 is involved in the invasion of glioma cells as an upstream regulator of MMP-2. When FoxM1 expression is downregulated in glioma cells, MMP-2 expression also decreases, affecting tumor invasion and metastasis (39). In the present study, Spearman's rank correlation analysis revealed that CEP55 protein expression was positively correlated with p-Akt, FoxM1 and MMP-2 levels in astrocytoma. These results suggested that CEP55 may 
interact with the other three proteins to regulate the invasive growth of astrocytoma.

High expression of CEP55 and FoxM1 is linked to the occurrence, development and malignancy of tumors and to poor prognosis. For instance, Jiang et al (40) indicated that patients with non-small-cell lung cancer with higher CEP55 expression had a less favorable prognosis than patients with lower CEP55 expression. In breast cancer, the expression levels of CEP55 were positively associated with the degree of malignancy and high expression of CEP55 was indicated to be associated with poor prognosis $(41,42)$. In addition, Dai et al (43), indicated that FoxM1 expression was significantly increased in solid malignant tumors (including breast, gastric and pancreatic cancer) and was associated with poor prognosis. Furthermore, Wen et al (35) reported that FoxM1 promotes the proliferation, invasion and metastasis of ovarian cancer cells, resulting in poor prognosis. The present study indicated that high levels of CEP55, p-Akt, FoxM1 and MMP-2 were associated with shorter overall survival. Further multivariate analysis confirmed that CEP55 and FoxM1 expression, tumor grade and patient age were independent prognostic factors in patients with glioma.

In conclusion, CEP55, p-Akt, FoxM1 and MMP-2 levels were increased in astrocytoma and these targets may have important roles in the progression of this disease. Furthermore, strong correlations were observed among CEP55, p-Akt, FoxM1 and MMP-2 in patients with astrocytoma. It may therefore be proposed that CEP55 upregulates MMP-2 expression, which promotes the invasion of astrocytoma cells by mediating the Akt/FoxM1 signaling pathway. The results of the overall survival analysis revealed that CEP55, p-Akt, FoxM1 and MMP-2 levels, as well as tumor grade and patient age were associated with patient prognosis. Furthermore, CEP55 and FoxM1 expression, tumor grade and patient age were independent prognostic factors predicting poor outcomes in patients with astrocytoma. Taken together, the present results indicated that these four targets have crucial roles in the progression and prognosis of human astrocytoma. CEP55 and FoxM1 may be potential therapeutic targets.

\section{Acknowledgements}

Not applicable.

\section{Funding}

The present study was supported by the Hebei Medical Practical Technology Tracking Project (grant no. G2018037), the Hebei Science and Technology Plan Project (Special Health Service and Biomedical Project; grant no. 17277708D) and the Natural Science Foundation of Hebei Province (grant no. H2019206709).

\section{Availability of data and materials}

The datasets used during the present study are available from the corresponding author upon reasonable request.

\section{Authors' contributions}

YL, SN and JW were responsible for the conception and design of the study and critically revised the manuscript for important intellectual content. SN, JC, WG and YC were responsible for the data acquisition, selection and analysis and clinical interpretation of the data. SN, LL, QZ, YL, HS, LX, LS and WW performed the experiments and analyzed the data. All authors contributed to the writing of the manuscript. All authors read and approved the final version of manuscript.

\section{Ethics approval and consent to participate}

The study was approved by the Ethics Committee of The Second Hospital of Hebei Medical University. All patients or their guardians provided written informed consent.

\section{Patient consent for publication}

Not applicable.

\section{Competing interests}

The authors declare that they have no competing interests.

\section{References}

1. Surawicz TS, Davis F, Freels S, Laws ER Jr and Menck HR: Brain tumor survival: Results from the national cancer data base. J Neurooncol 40: 151-160, 1998.

2. Ostrom QT, Gittleman H, Fulop J, Liu M, Blanda R, Kromer C, Wolinsk Y, Kruchko C and Barnholtz-Sloan JS: CBTRUS statistical report: Primary brain and central nervous system tumors diagnosed in the United States in 2008-2012. Neuro Oncol 17 (Suppl 4): iv1S-iv62S, 2015.

3. Agnihotri S, Alddape KD and Zadeh G: Isocitrate dehydrogenase status and molecular subclasses of glioma and glioblastoma. Neurosurg Focus 37: E13, 2014.

4. Yan H, Parsons DW, Jin G, McLendon R, Rasheed BA, Yuan W, Kos I, Batinic-Haberle I, Jones S, Riggins GJ, et al: IDH1 and IDH2 mutations in gliomas. N Engl J Med 360: 765-73, 2009.

5. Louis DN, Perry A, Reifenberger G, von Deimling A, Figarella-Branger D, Cavenee WK, Ohgaki H, Wiestler OD, Kleihues P and Ellison DW: The 2016 world health organization classification of tumors of the central nervous system: A summary. Acta Neuropathol 131: 803-820, 2016.

6. Fabbro M, Zhou BB, Takahashi M, Sarcevic B, Lal P, Graham ME, Gabrielli BG, Robinson PJ, Niqq EA, Ono Y and Khanna KK: Cdk1/Erk2- and Plk1-dependent phosphorylation of a centrosome protein, Cep55, is required for its recruitment to midbody and cytokinesis. Dev cell 9: 477-488, 2005.

7. Singh PK, Srivastava AK, Rath SK, Dalela D, Goel MM and Bhatt ML: Expression and clinical significance of centrosomal protein 55 (CEP55) in human urinary bladder transitiona-l cell carcinoma. Immunobiology 220: 103-108, 2015.

8. Jiang W, Wang Z and Jia Y: CEP55 overexpression predicts poor prognosis in patients with locally advanced esophageal squamous cell carcinoma. Oncol Lett 13: 236-242, 2017.

9. Qi J, Liu G and Wang F: High levels of centrosomal protein 55 expression is associated with poor clinical prognosis in patients with cervical cancer. Oncol Lett 15: 9347-9352, 2018.

10. Tao J, Zhi X, Tian Y, Li Z, Zhu Y, Wang W, Xie K, Tang J, Zhang $\mathrm{X}$, Wang $\mathrm{L}$ and $\mathrm{Xu} \mathrm{Z}$ : CEP55 contributes to human gastric carcinoma by regulating cell proliferation. Tumour Biol 35: 4389-4399, 2014

11. Chen CH, Lu PJ, Chen YC, Fu SL, Wu KJ, Tsou AP, Lee YCG, Lin TCE, Hsu SL, Lin WJ, et al: FLJ10540-elicited cell transformation is through the activation of PI3-kinase/AKT pathway. Oncogene 26: 4272-4283, 2007.

12. Jeffery J, Sinha D, Srihari S, Kalimutho M and Khanna KK: Beyond cytokinesis: The emerging roles of CEP55 in tumorigenesis. Oncogene 35: 683-690, 2016.

13. Xu L, Xia C, Sheng F, Sun Q, Xiong J and Wang S: CEP55 promotes the proliferation and invasion of tumour cells via the AKT signalling pathway in osteosarcoma. Carcinogenesis 39: 623-631, 2018. 
14. Chen CH, Lai JM, Chou TY, Chen CY, Su LJ, Lee YC, Cheng TS, Hong YR, Chou CK, Whang-Peng J, et al: VEGFA upregulates FLJ10540 and modulates migration and invasion of lung cancer via PI3K/AKT pathway. PLoS One 4: e5052, 2009.

15. Kaestner KH, Knochel W and Martinez DE: Unified nomenclature for the winged helix/forkhead transcription factors. Genes Dev 14: 142-146, 2000.

16. Chen H, Wang J, Yang H, Chen D and Li P: Association between FOXM1 and hedgehog signaling pathway in human cervical carcinoma by tissue microarray analysis. Oncol Lett 12: 2664-2673, 2016.

17. Wei P, Zhang N, Wang Y, Li D, Wang L, Sun X, Shen C, Yang Y, Zhou $\mathrm{X}$ and Du X: FOXM1 promotes lung adenocarcinoma invasion and metastasis by upregulating SNAIL. Int J Biol Sci 11: 186-198, 2015.

18. Liu M, Dai B, Kang SH, Ban K, Huang FJ, Lang FF, Aldape KD, Xie TX, Pelloski CE, Xie K, et al: FoxM1B is overexpressed in human glioblastomas and critically regulates the tumorigenicity of glioma cells. Cancer Res 66: 3593-3602, 2006.

19. Major ML, Lepe R and Costa RH: Forkhead box M1B transcriptional activity requires binding of Cdk-cyclin complexes for phosphorylation-dependent recruitment of p300/CBP coactivators. Mol Cell Biol 24: 2649-2661, 2004.

20. Li Y, Zhang T, Zhang Y, Zhao X and Wang W: Targeting the FOXM1-regulated long noncoding RNA TUG1 in osteosarcoma. Cancer Sci 109: 3093-3104, 2018.

21. Wang Z, Li Y, Ahmad A, Banerjee S, Azmi AS, Kong D, Wojewoda C, Miele L and Sarkar FH: Down-regulation of Notch-1 is associated with Akt and FoxM1 in inducing cell growth inhibition and apoptosis in prostate cancer cells. J Cell Biochem 112: 78-88, 2011.

22. Miyashita A, Fukushima S, Nakahara S, Yamashita J, Tokuzumi A, Aoi J, Ichihara A, Kanemaru H, Jinnin M and Ihn H: Investigation of FOXM1 as a potential new target for Melanoma. PLoS One 10: e0144241, 2015.

23. Chen W, Yuan K, Tao ZZ and Xiao BK: Deletion of forkhead BoxM1 transcription factor reduces malignancy in laryngeal squamous carcinoma cells. Asian Pac J Cancer Prev 12: 1785-1788, 2011.

24. Ahmad A, Wang Z, Kong D, Ali S, Li Y, Banerjee S, Ali R and Sarkar FH: FoxM1 down-regulation leads to inhibition of proliferation, migration and invasion of breast cancer cells through the modulation of extra-cellular matrix degrading factors. Breast Cancer Res Treat 122: 337-346, 2010.

25. Chen $\mathrm{CH}$, Chien $\mathrm{CY}$, Huang CC, Hwang $\mathrm{CF}$, Chuang $\mathrm{HC}$ Fang FM, Huang HY, Chen CM, Liu HL and Huang CY: Expression of FLJ10540 is correlated with aggressiveness of oral cavity squamous cell carcinoma by stimulating cell migration and invasion through increased FOXM1 and MMP-2 activity. Oncogene 28: 2723-2737, 2009.

26. Ma S, Pang C, Song L, Guo F and Sun $\mathrm{H}$ : Activating transcription factor 3 is overexpressed in human glioma and its knockdown in glioblastoma cells causes growth inhibition both in vitro and in vivo. Int J Mol Med 35: 1561-1573, 2015.

27. Ma Q, Zhou B and Zhang J: Expression and clinical significance of FoxM1 and Cep55 in basal-like breast cancer. Hebei Med J 37: 5-9, 2015. (In Chinese).

28. Chen L, Cao T, Li S, Luo L and Yang Y: Expression of FOXO3a in epithelial ovarian cancer and its correlation with clinicopathological features. Med J West China 31: 670-678, 2019. (In Chinese).

29. Chen GQ, Yao ZW and Luo X: Expression and clinical significance of FOXM1 in epithelial ovarian carcinoma. Life Sci Res 15: 70-74, 2011. (In Chinese).

30. Zhong Z, He ZW, Qiu Y, Ren NJ, Gao HB and Zhang K: Expression and corelation of MMP-2 and Ki-67 in human glioma tissues. Chin J Cancer Prev T Reat 17: 1070-1072, 2010. (In Chinese).
31. Shimizu Y, Segawa T, Inoue T, Shiraishi T, Yoshida T, Toa Y, Yamada T, Kinukawa N, Terada N, Kobayashi H, et al: Increased Akt and phosphorylated Akt expression are associated with malignant biological features of prostate cancer in Japanese men. BJU Int 100: 685-690, 2007.

32. Rychahou PG, Kang J, Gulhati P, Doan HQ, Chen LA, Xiao SY, Chung DH and Evers BM: Akt2 overexpression plays a critical role in the establishment of colorectal cancer metastasis. Proc Natl Acad Sci USA 105: 20315-20320, 2008.

33. Kim IM, Ackerson T, Ramakrishna S, Tretiakova M, Wang IC, Kalin TV, Major ML, Gusarova GA, Yoder HM, Costa RH and Kalinichenko VV: The Forkhead Box $\mathrm{m} 1$ transcription factor stimulates the proliferation of tumor cells during development of lung cancer. Cancer Res 66: 2153-2161, 2006.

34. Janus JR, Laborde RR, Greenberg AJ, Wang VW, Wei W, Trier A, Olsen SM, Moore EJ, Olsen KD and Smith DI: Linking expression of FOXM1,CEP55 and HELLS to tumorigenesis in oropharyngeal squamous cell carcinoma. Laryngoscope 121: 2598-2603, 2011

35. Wen N, Wang Y, Wen L, Zhao SH, Ai ZH, Wang Y, Wu B, Lu HX, Yang H, Liu WC and Li Y: Overexpression of FOXM1 predicts poor prognosis and promotes cancer cell proliferation, migration and invasion in epithelial ovarian cancer. J Transl Med 12: 134, 2014.

36. Sullu Y, Demiraq GG, Yildirim A, Karaqoz F and Kandemir B Matrix metalloproteinase-2 (MMP-2) and MMP-9 expression in invasive ductal carcinoma of the breast. Pathol Res Pract 207: 747-753, 2011

37. Coticchia CM, Curatolo AS, Zurakowski D, Yang J, Daniels KE, Matulonis UA and Moses MA: Urinary MMP-2 and MMP-9 predict the presence of ovarian cancer in women with normal CA125 levels. Gynecol Oncol 123: 295-300, 2011.

38. Peng WJ, Zhang JQ, Wang BX, Pan HF, Lu MM and Wang J: Prognostic value of matrix metalloproteinase 9 expression in patients with non-small cell lung cancer. Clin Chim Acta 413: 1121-1126, 2012

39. Dai B, Kang SH, Gong W, Liu M, Aldape KD, Sawaya R and Huang S: Aberrant FoxM1B expression increases matrix metalloproteinase- 2 transcription and enhances the invasion of glioma cells. Oncogene 26: 6212-6219, 2007.

40. Jiang C, Zhang Y, Li Y, Lu J, Huang Q, Xu R, Feng Y and Yan S: High CEP55 expression is associated with poor prognosis in non-small-cell lung cancer. Onco Targets Ther 11: 4979-4990, 2018.

41. Inoda S, Hirohashi Y, Torigoe $\mathrm{T}$, Nakatsugawa M, Kiriyama $\mathrm{K}$, Nakazawa E, Harada K, Takasu H, Tamura Y, Kamiguchi K, et al: Cep55/c10orf3, a tumor antigen derived from a centrosome residing protein in breast carcinoma. J Immunother 32: 474-485, 2009.

42. Coutant C, Rouzier R, Qi Y, Lehmann-Che J, Bianchini G, Lwamoto T, Hortobagyi GN, Symmans WF, Uzan S, Andre F, et al: Distinct $\mathrm{p} 53$ gene signatures are needed to predict prognosis and response to chemotherapy in ER-positive and ER-negative breast cancers. Clin Cancer Res 17: 2591-2601, 2011.

43. Dai J, Yang L, Wang J, Xiao Y and Ruan Q: Prognostic value of FOXM1 in patients with malignant solid tumor: A meta-analysis and system review. Dis Markers 2015: 352478, 2015.

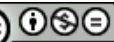

This work is licensed under a Creative Commons Attribution-NonCommercial-NoDerivatives 4.0 International (CC BY-NC-ND 4.0) License. 